\title{
Perceptions of the 2019 Canada's Food Guide: a qualitative study with parents from Southwestern Ontario
}

\author{
Ana Carolina Barco Leme, Amar Laila, Sophia Hou, Regina Mara Fisberg, David W.L. Ma, Mauro Fisberg, \\ and Jess Haines
}

\begin{abstract}
In January 2019, Health Canada released a revised Canada's Food Guide (CFG). This study aimed to understand the perceptions of the 2019 CFG among Canadian parents with children aged 2-12 years. From October 2019-January 2020, 8 focus groups with parents from Southwestern Ontario were conducted using a semi-structured interview script focused on understanding perceptions of the 2019 CFG. A hybrid thematic approach with inductive and deductive analyses was used. Forty parents $(72.5 \%$ mothers, $77.5 \%$ white) with diverse levels of education and income participated. Most parents were aware of the 2019 CFG. Positive perceptions of the 2019 CFG were that the guide was visually appealing and less biased from the food industry compared with previous guides. Parents also reported that the focus on eating behaviours could support healthy eating among their families. Negative perceptions included insufficient information about plantbased proteins, removal of milk and alternatives food group, and lack of representation of various cultures in the guide. Challenges to following the CFG recommendations, including time constraints and limited knowledge regarding how to identify and prepare plant-based proteins, were discussed. Parent perceptions of the CFG can help inform public health policies and behavioural-change strategies designed to support adherence to the 2019 CFG recommendations.
\end{abstract}

\section{Novelty:}

- Awareness of the 2019 Canada's Food Guide (CFG) was high.

- Parents identified that the 2019 CFG was visually appealing and less biased from the food industry.

- Concerns about the recommendations of plant-based proteins, "exclusion" of dairies, and lack of cultural representation.

Key words: Canada’s Food Guide, parents, perceptions, meals, focus groups, healthy eating.

Résumé : En janvier 2019, Santé Canada a publié une version révisée du Guide alimentaire canadien (GAC). Cette étude a pour objectif de comprendre les perceptions du GAC 2019 chez les parents canadiens ayant des enfants âgés de 2 à 12 ans. D'octobre 2019 à janvier 2020, huit groupes de discussion avec des parents du Sud-Ouest de l'Ontario participent à un script d'entretien semi-structuré axé sur la compréhension des perceptions du GAC 2019. Une approche thématique hybride avec des analyses inductives et déductives est utilisée. Quarante parents participent à cette étude (mères, 72,5 \%, race blanche, 77,5 \%); ils ont divers niveaux de scolarisation et de revenus. La plupart des parents sont au courant du GAC 2019. Les perceptions positives du GAC 2019 sont que le guide est visuellement attrayant et moins biaisé par l'industrie alimentaire comparativement aux guides précédents. Les parents mentionnent également que l'accent mis sur les comportements alimentaires pourrait favoriser une alimentation saine au sein de leur famille. Les perceptions négatives évoquent une information insuffisante sur les protéines végétales, l'élimination du lait et des substituts du groupe d'aliments ainsi que le manque de représentation de diverses cultures dans le guide. Les discussions portent sur les défis liés au suivi des recommandations du GAC, y compris les contraintes de temps et les connaissances limitées sur la façon d'identifier et de préparer les protéines végétales. Les perceptions des parents sur le GAC peuvent aider à éclairer les politiques de santé publique et les stratégies de changement de comportement conçues pour soutenir le respect des recommandations du GAC 2019. [Traduit par la Rédaction]

Les nouveautés :

- La notoriété du Guide alimentaire canadien (GAC) 2019 est élevée.

- Les parents mentionnent que le GAC 2019 est visuellement attrayant et moins biaisé par l'industrie alimentaire.

Received 5 June 2021. Accepted 12 August 2021.

A.C. Barco Leme. Family Relations and Applied Nutrition, University of Guelph, Guelph, ON N1G 2W1, Canada; Center of Excellence in Nutrition and Feeding Difficulties, PENSI Institute/Sabará Children’s Hospital, São Paulo, 01228-200, Brazil.

A. Laila, S. Hou, and J. Haines. Family Relations and Applied Nutrition, University of Guelph, Guelph, ON N1G 2W1, Canada.

R.M. Fisberg. Departament of Nutrition, School of Public Health, University of São Paulo, São Paulo, 01246-904, Brazil.

D.W.L. Ma. Department of Human Health and Nutrition Sciences, University of Guelph, Guelph, ON N1G 2W1, Canada.

M. Fisberg. Center of Excellence in Nutrition and Feeding Difficulties, PENSI Institute/Sabará Children’s Hospital, São Paulo, 01228-200, Brazil.

Corresponding author: Ana Barco Leme (email: acarol.leme@gmail.com).

() 2021 The Author(s). This work is licensed under a Creative Commons Attribution 4.0 International License (CC BY 4.0), which permits unrestricted use, distribution, and reproduction in any medium, provided the original author(s) and source are credited. 
- Il y a des préoccupations concernant les recommandations de protéines végétales, "l'exclusion » des produits laitiers et le manque de représentation culturelle.

Mots-clés : Guide alimentaire canadien, parents, perceptions, repas, groupes de discussion, alimentation saine.

\section{Introduction}

Canada's Food Guide (CFG) has provided dietary guidance to Canadians since 1942. The CFG serves as the basis for school curricula across the country as well for clinical care and public health interventions and policies. A revised version of the CFG was released in January 2019. Revisions were substantive shifting to a focus on dietary patterns rather than nutrients intake and a change from 4 food groups in the 2007 guide to 3 food groups and included fruit and vegetables, whole grains, and protein foods in the 2019 CFG (Health Canada 2019). Within protein foods, the 2019 CFG recommends eating plant-based protein foods more often.

Previous CFGs have been criticized for food industry's influence in the development process (Fabbri et al. 2018; Hui 2017; Seed and Rocha 2018). Critics have expressed concern that industry involvement may result in recommendations that reflect industry preferences rather than scientific evidence and that this industry involvement could undermine Canadians' trust in the CFG recommendations. Unlike previous revisions of the Food Guide, the revision process for the 2019 Food Guide did not include direct consultations with industry representatives (Health Canada 2021). Industry representatives were invited to participate in the online public consultations, which were open to all stakeholders and members of the public (Health Canada 2021).

Limited published research has examined Canadians' perceptions of the 2019 CFG and/or the process used to create the 2019 CFG. A 2019 survey of over 1000 Canadian adults found that $74 \%$ of respondents stated they were aware of the 2019 CFG. Over $50 \%$ perceived that the 2019 CFG provides realistic and practical dietary guidance and 53\% reported that they believed the dietary recommendations provided in the CFG were based on the best scientific evidence (Charlebois et al. 2021). While this survey provides insight into Canadian adults' perceptions of the 2019 CFG, the use of close-ended survey items limits the depth of understanding of respondents' perceptions of the 2019 CFG. A qualitative study with 8 pregnant women found that two-thirds of the women were familiar with the 2019 CFG; the women reported that the 2019 CFG was "appealing and healthy" (Patel and Mannion 2019).

Building on these findings to explore perceptions of the 2019 CFG within additional population subgroups, such as parents, can help inform targeted health promotion strategies. Parents play a critical role in determining children's dietary intake by controlling their home food environment as well as their feeding practices (Wijayaratne et al. 2021; Zarychta et al. 2020). Understanding how parents perceive and interpret the 2019 CFG can inform interventions and policies designed to influence parents' own dietary intake as well as their children's intake (Paquette 2005). Thus, the aim of the present study was to determine perceptions of the 2019 CFG among Canadian parents with children aged 2-12 years using qualitative research methods.

\section{Materials and methods}

Implementation and reporting of this study adhered to the guidelines outlined in the Consolidated Criteria for Reporting Qualitative Research (COREQ) (Buus and Perron 2020). Ethics approval was obtained from the Research Ethics Board at the University of Guelph, Guelph, Canada (\#19-07-023).

\subsection{Study design}

A cross-sectional qualitative design pertaining to a moment in time using a focus group methodology was employed, as focus groups are an ideal way to explore parents' perceptions of the 2019 CFG and how the CFG supports healthy eating and meal planning among families. Focus groups can be conducted in naturalistic settings, which may stimulate more openness and truthfulness in discussion, as opposed to experimental situations (Kitzinger 1995; O.Nyumba et al. 2018). Additionally, participants' group interactions can illicit information and insights that are less accessible during individual interviews (Morgan 1993). Probing by the moderator can also allow for a more in-depth exploration of unanticipated responses as well as an opportunity to clarify and understand responses (Kitzinger 1995; Krueger and Casey 2015; O.Nyumba et al. 2018).

\subsection{Participants and settings}

Eligible participants were parents of children aged 2 to 12 years old, who were fluent in reading, writing and speaking in English. Participants with children in this age range were selected because behaviours established in childhood persist into adulthood, and family plays an important role in establishing healthy eating behaviours early (Ontai et al. 2020). Parents were selected using a purposive sampling method (i.e., homogeneous on a particular characteristic; in this case parents of preschool- and school-age children) and recruited from social media and local community agencies that serve parents and/or families in the Guelph/Eramosa area. Recruitment materials included: flyers distributed around the local community and posts on social media (Instagram, Facebook, and Twitter).

Eligible participants emailed research assistants to express their interest in the study and the research assistant then followed up via email to invite them to attend a focus group that was scheduled at various times. Two focus groups included only mothers, 5 were mixed in terms of parent gender, and 1 focus group included only fathers. Purposive snowball sampling was used to recruit fathers for a father-specific focus group due to the low number of fathers in the mixed focus groups. Focus groups were conducted until the moderators felt that data saturation was achieved, which was confirmed during data analysis (Faulkner and Trotter 2017). Demographic characteristics were collected via a survey prior to the start of a single focus group meeting, and included age, gender, race, marital status, household income, number of children, and age of children. Focus groups were conducted at local community centres and at the university. All participants provided written informed consent prior to participating in the focus groups. Participants received a CA $\$ 30$ grocery gift card as a thank you for participating in the study in recognition of their time and travel costs.

\subsection{Data collection}

Focus groups were conducted from October 2019-January 2020. Each focus group included between 5-9 participants, with focus groups lasting from 52 minutes to 1 hour and 38 minutes. Focus groups were audio recorded and transcribed. All groups were conducted by 1 of 2 moderators, who were trained and experienced in focus group methodology. An assistant moderator attended all sessions to aid in note-taking and time management. Prior to the study, no relationship between moderators and participants were established. The structured discussion framework and prompts were developed by the research team to facilitate discussion and reflection on the overall aims of the qualitative study. Questions were created using Krueger and Casey's guide (Krueger and Casey 2015), which included an opening question, introductory question, transition and key questions, and a 
concluding question (Supplementary file $S 1^{1}$ ). The content of the questions was informed by the content and recommendations of the 2019 CFG (Health Canada 2019). The questions were pretested with study staff members and revisions were made where necessary. A total of 8 questions were asked, but only the responses to 6 questions are included in this paper. Specifically, responses to the questions that explored participants' perceptions of the 2019 CFG and how the CFG supports healthy eating and meal preparation in families were the focus of this manuscript. Questions related to the CFG eating behaviour recommendations, i.e., "Cook more often" were not included in this analysis. To facilitate the conversation, participants were provided with a copy of 2019 CFG snapshot during the focus group. Probes were used to further clarify and explore participants' responses. A verbal summary of responses was provided to parents by the moderator at the closing minutes of each focus group session. Parents were asked to review the summary and were given an opportunity to provide additional comments that might have been forgotten. Once the parents had left the group sessions, the moderator and the assistant moderator had a brief discussion to compare notes and confirm that their perceptions of responses were similar.

\subsection{Data analysis}

Parents' socio-demographic characteristics were described as frequencies (percentages) for each variable: age, sex, race, marital status, educational background, household (annual) income, number of children and children's age. Analysis focused on the audio transcripts with the written notes used only to clarify comments, if the audio and resulting transcript from the focus group were not clear. Audio transcripts of the focus groups were analyzed independently by 3 trained coders (A.C.B.L., A.L., and S.H.) using a hybrid thematic approach of deductive and inductive analyses (Braun and Clarke 2006) allowing for an in-depth exploration of data-driven and theory-driven concepts. Each of the coders read all of the transcripts and started to create codes using an open coding process with groups serving as the unit of analysis. The coders held multiple group meetings to discuss the transcripts and their codes. Through these meetings, the coders created a selective coding template, which was then applied to identify meaningful text units. Coders met routinely through the coding process and the coding scheme was revised and further expanded upon, as new inductive codes were assigned to segments of data describing a new theme. Following the coding of all focus group transcripts, the coders met again to identify themes and patterns in the data. This interpretative phase enabled the generation of overarching themes and subthemes to capture the multifaceted views, experiences, and insights of parents. NVIVO software (version 12, QSR International) was used to assist with the organizational aspects of the qualitative data analysis.

\section{Results}

In total, 40 parents participated (29 mothers and 11 fathers). Most participants were between 35-44 years old (57.5\%), white (77.5\%), born in Canada (75.0\%), married (70.0\%), and had 2 children (50.0\%). Education levels ranged among the participants; $15 \%$ had a high school degree or less, $22.5 \%$ completed some college or university, $20.0 \%$ graduated from college, and $42.5 \%$ graduated from university/completed a post-graduate degree. Similarly, income levels ranged among the participants with $17.5 \%$ reporting an annual household income below $\$ 39000$ and $12.5 \%$ reporting an annual household income of over $\$ 150000$ (Table 1).

\subsection{Awareness of the 2019 Canada food guide (CFG)}

Most of the parents reported that they were aware of the 2019 CFG. They reported seeing or being exposed to the food guide
Table 1. Socio-demographic characteristics of parents' participating in the focus group (Guelph, Ontario, Canada; $n=40)$.

\begin{tabular}{|c|c|}
\hline Characteristic & Frequency (\%) \\
\hline \multicolumn{2}{|l|}{ Age } \\
\hline $25-34$ & $15(37.5)$ \\
\hline $35-44$ & $23(57.5)$ \\
\hline $45-54$ & $2(5.0)$ \\
\hline \multicolumn{2}{|l|}{ Gender } \\
\hline Female & 29 (72.5) \\
\hline Male & $11(27.5)$ \\
\hline \multicolumn{2}{|l|}{ Race } \\
\hline White & $31(77.5)$ \\
\hline Non-white & $9(22.5)$ \\
\hline \multicolumn{2}{|l|}{ Annual household income } \\
\hline Less than $\$ 10000-\$ 39000$ & $7(17.5)$ \\
\hline$\$ 40000-\$ 59000$ & $6(15)$ \\
\hline$\$ 60000-\$ 79000$ & $7(17.5)$ \\
\hline$\$ 80000-\$ 99000$ & $6(15)$ \\
\hline$\$ 100000-\$ 149000$ & $6(15)$ \\
\hline$\$ 150000$ or more & $5(12.5)$ \\
\hline Did not report & $3(7.5)$ \\
\hline \multicolumn{2}{|l|}{ Marital status } \\
\hline Married or living with a partner & $34(85.0)$ \\
\hline Separated & $4(10.0)$ \\
\hline Single & $2(5.0)$ \\
\hline \multicolumn{2}{|l|}{ Education level } \\
\hline$\leq$ High school & $6(15)$ \\
\hline Some college or university & $17(42.5)$ \\
\hline$\geq$ University degree & $17(42.5)$ \\
\hline \multicolumn{2}{|l|}{ Number of children } \\
\hline 1 & $8(20.0)$ \\
\hline 2 & $20(50)$ \\
\hline$\geq 3$ & $12(30.0)$ \\
\hline \multicolumn{2}{|l|}{ Country of birth } \\
\hline Canada & $30(75.0)$ \\
\hline Other & $10(25.0)$ \\
\hline \multicolumn{2}{|l|}{$\begin{array}{l}\text { Years in Canada; among those not } \\
\text { born in Canada, } n=10\end{array}$} \\
\hline$\leq 5$ & $5(50.0)$ \\
\hline$>5$ & $5(50.0)$ \\
\hline
\end{tabular}

through their workplace, children's schools, from friends and family, and on the news: "I just saw it on CBC News but I haven't actually read much about it." Other parents identified that they accessed the food guide through the Health Canada website or from online searches: “(. ..) looking it up on the website”, “(...) I just search in Google" and "(...) I was on the website [referring to Health Canada], and then I saw the picture book. I'm a visual person."

\subsection{Perceived changes with the 2019 CFG}

The majority of the parents identified that the 2019 CFG was quite different from previous versions of the CFG: "ah, it was such a big change from what it was, say, when I was a kid, kind of thing, seeing it in school." Many noted the focus on a more plantbased diet with more fruits and vegetables, and getting protein from sources other than meat: "Like, it was more like, fruits and vegetables in everyone's face, kind of thing" and "I feel like they were focusing more on, like, plant-based diets.”

\subsection{Positive perception of the 2019 CFG}

\subsubsection{Visually appealing}

Overall parents reported that they liked the images included in the 2019 CFG, as 1 participant stated: “(. . ) liked how these

\footnotetext{
${ }^{1}$ Supplementary data are available with the article at https://doi.org/10.1139/apnm-2021-0414.
} 
visuals were using real food this time, instead of illustrations. You know, I thought it was more helpful (...)", while others refer to the visual variety of foods shown in the 2019 CFG to help overcome feeding challenges:

(. . .) I do think that visually, sometimes, you get stuck, especially as a parent feeding your kid, because they're so picky. So just seeing so many types of carbs and so many types of likes, fresh fruits and vegetables, like, more complex carbs and all these sources of protein, helps you think oh, outside the box (...) visually, I find, it's very compelling, and it's a useful tool.

\subsubsection{Development of the food guide was not biased by industry and government interests}

Some of the parents viewed the 2019 CFG as focusing less on industry interests than previous food guides: “(...) Canada's industry is heavy on cattle and dairy. But it kind of moved away from that which is, which makes me think it's impartial and done a good job", and on the potential to influence the agriculture industry:

You feel that you're being given unbiased information, and also, with whole families of farmers and stuff, to see the recommendations really change, could really influence Canadian farming and agriculture, without, and it takes, you could really influence how things are purchased, and the agricultural system is slower to adapt.

\subsubsection{CFG focused on aspects of eating behaviours}

Parents reported that they liked that the 2019 CFG included recommendations focused on eating behaviours:

(...) easy to follow. I do really like how it says things like 'enjoy your food' and 'eat meals with others.' Cause I do think, like, hmm, ... but I do think that it's like, important to enjoy your meal, like, as a family, and the whole aspect of it, and also that, people can get too obsessed with eating healthy, that it can, I feel, almost be like counterproductive, if you're constantly, like, worrying about what you're eating.

\subsubsection{Focus on diets that are good for the environment}

Other favourable facets reported by parents were that CFG recommendations align well with environmental messages:

(. . .) I keep thinking it's interesting that it lines up with, ah, like climate scientists' recommendations, or like, acknowledgement of the toll animal agriculture takes on the planet, given, like, the climate change emergency. And I don't, I'm not a vegan. I mean, I'll still eat, like, local meat. But I think it lines up with that evidence too, just aside from this topic (...) it is very relevant as well.

\subsection{Negative perceptions of the 2019 CFG}

\subsubsection{Insufficient guidance regarding plant-based proteins}

Parents expressed concern that the 2019 CFG did not provide sufficient guidance regarding the quality of protein provided by plant-based sources:

(...) I don't think they emphasize enough that like, a protein from chickpeas is not the same as protein that you're getting from something else. So, like, all protein is different. So that's my only issue with it, is that you, like, the protein in meat is more bioavailable to your body, than it is from beans. (...) So that's my only thing is someone who doesn't know that would think that they are eating beans and getting lots of protein, when you have to eat, like, five cups of beans to get the same amount of protein as, like, a piece of meat.

\section{Another parent stated:}

It's kind of nice that they're trying to, I think ... gently transition people into maybe thinking about [eating more plantbased protein sources]. I think maybe they need to also, like, maybe give people on how to do it. Because, like, you're supposed to, so then you get your full amino acid profile, you need to basically pair them, right?

\subsubsection{Where is the dairy?}

Some parents expressed concern about the perceived omission of milk and dairy in the 2019 CFG: "I feel like they're putting a negative spin on dairy, by not including it at all." Another parent stated:" (. . .) so it was dairy that was excluded. I find the dairy piece really interesting, cause as a parent, it's ingrained into you, from a child, like, dairy is good for you, good for bones and teeth." Another parent identified the fact that the food guide no longer had a milk and alternatives food group may be confusing or concerning to parents: "I think the only thing that might be concerning to some parents though is like, cutting out the dairy. They might be confused . . like, it's been in there forever, and all of a sudden, it's just not there." Some parents also wondered whether their children would get sufficient protein if they did not eat dairy: "Cause I find my children would much more be prone to eating cheese, yogurt, milk, that kind of stuff."

\subsubsection{Lack of cultural representation in the food guide}

Parents described that the guidelines did not fit their cultural traditions. As a mother who had moved to Canada from Africa described: “(...) That really doesn't work for my family. In our culture, we eat like, more, like, grain stuff, like, teff." Parents also discussed how the CFG should include recommendations (and images) that reflect the food culture of different ethnic backgrounds: "(...) I think it would be really interesting to have a panel of really, like, ethnically diverse people, from really different backgrounds and what all of those different opinions would be on the food guide."

\subsection{Perception of the CFG as science-based was mixed}

Some parents said that the 2019 CFG is evidence-based - "I know a lot of research goes into this though, and a lot of work. It's not, this is not a whim that someone put together. Someone did a lot of work to make sure that this was following current trends, scientifically, I assume" - reporting the trust on the government: "I haven't looked at any of the sources or anything behind it. (...) like to trust that, you know, Health Canada, which is printed all over it", as well as collaborations with the tripartite industry, government and academia:

My understanding of the process is they did do a view of the most recent research and they did some public consultations as well as industry consultations. So, in the best of their ability, they did consult the research. It wasn't just somebody, you know, making it up (laugh) (...) they actually had a team of people, internal and external to the process, that shaped this.

Alternatively, other parents expressed concern about how scientific evidence is always changing making it hard to determine if the dietary recommendations are correct:

(...) again, if you think about tofu, and you read, and then 'No, tofu is good.' and then not every day. And so, sometimes, I don't know what to, what to eat, really. Because if you go to fish, no fish, because of the mercury in the fish. If you go to tofu, it's this, and this - so, ach, I don't know. But it's good that they are, at least you can eat a little bit of everything. I don't know. 


\subsection{Challenges to meeting the 2019 CFG recommendations}

\subsubsection{Challenges to eating more plant-based proteins}

Parents perceived challenges in meeting the recommendation of "Choose protein foods that come from plants more often", including not being aware of what foods are plant-based:

I think just, like, getting more like, having more accessibility to where the proteins are in the plants, like, in what plants. Cause, you know, once you get passed, maybe, you know, lentils and I don't know, once you get past lentils, it's, 'Where do you go?' (laugh) I think that's part of the problem too, right, just understanding where, where the protein plants are.

Another parent said: "So, I mean, people think beans are like, 'Oh, like, brown beans.' But there's a bazillion different kinds of beans out there. And people don't, aren't necessarily aware of that, so I think maybe people need to be pointed in the right direction."

Parents identified that processed plant-based products helped them to identify and access plant-based foods: “(...) we have a lot of alternatives. And I have been leaning towards plant-based alternatives a lot more, that are processed." However, parents also discussed the fact these processed plant-based food products may not be the "healthiest": "(...) more brands of you know, the processed plant-based products are helpful. Maybe they aren't the best things, but I think just, like, getting more like, having more accessibility to where the proteins are in the plants."

Parents also talked about not knowing how to prepare plantbased meals: "I wouldn't even know how to prepare them, to be honest." Another parent stated "I think people need, they may need more tips, maybe, some quick tips on how to do it. And what to do, and I mean, not everyone knows how to cook vegetarian food very well, or at all. (laugh)" and other parent reported the difficulties on preparing plant-based foods:

(...) more focusing on the family aspect of it, in that it is more difficult to, I'm not a chef and I, very basic like 'Oh, meat, and there's your grains - '(laugh) And so, I don't know how to introduce a lot of these foods, (laugh) in our regular meals. Like, it might be easy for lunch to throw in some nuts, sort of thing. But, in a regular supper meal or dinner meal, I feel it is a little more difficult to (laugh) get in a lot of those.

\subsubsection{Recommendations a big departure from existing social and familial/cultural eating norms}

Parents identified that restricting intake of highly processed foods can be challenging due to their high availability and the social norms regarding children's eating:

(... I I have kids and I don't want to feel like they're being restricted or left out of certain things, right? I mean, they still eat hot dogs ... Like, I don't want to feel like I'm completely restricting them from it, because that's part of growing up.

Another parent stated: "And if they see another [child] with [snack food] or something. So, they said to me, 'Oh Mom, I want a [brand name of snack food]' So I go to the grocery and I buy them that."

A number of parents discussed how their familial and cultural norms regarding meat consumption could make a transition to eating more plant-based proteins challenging:

(...) That really doesn't work for my family. We grew up as farmers. Like, we ate a lot of meat. So, culturally, preparing meat was, preparing meat was a large portion of our meal, in a day (...) And my son really loves meat. And then, my partner also works for a meat company, so, (laugh) it doesn't really help there.

Another parent stated:

Well, it's just pretty hard in my house. My wife, my wife's father worked for (name) Beef until he retired. So, they had beef pretty much every dinner ... do I like, like vegetarian chili or devilled eggs or hardboiled eggs? Yeah. They're great. Not the first thing I think of, as far as protein.

\subsubsection{Time constraints}

Parents discussed that their busy schedule made it difficult to limit processed foods:

(...) Just the busy times, on nights of the weeks where there's a bunch of kids' activities. That tends to be the night where we end up with something more processed. It's usually specific days. If we have, like, all the swimming and soccer and dance, or whatever, on one night, then yeah, that night's going to be processed but the rest are pretty good.

Also, reinforcing the need to spend time with their children and engage in other leisure lifestyle behaviours, as reported by 1 parent:

... I mean, everything comes at a cost, and . . .like, it's great to eat healthy food and stuff like that. But it costs physical activity and it costs time with family. So, and you can try and squeeze it all - no you can't. I mean, (laugh) it's ah, so have I made the right choice? Maybe I should eat more frozen pizzas and go for a walk with my kid. (laugh) You know what I mean?

Another parent discussed the need to support parents to develop strategies to deal with time constraints:

There's ways to show people how to do things simply, like I said, like you suggested, like, preparing meals ahead of time, maybe on Sunday or something, especially lunches. Like, I do that. Or something. But I think maybe people need to just know how. It's great to cook more often, and it definitely is beneficial. It's just, people need to know how to incorporate this in their lives and make it routine. That's, again, like, that's like, people want to, they just sometimes can't.

\section{Discussion}

The current qualitative study identified Canadian parents' perceptions of the 2019 CFG. The findings indicate that most parents were aware of the 2019 guidelines and had both positive and negative perceptions regarding the 2019 CFG. Parents also identified some key challenges to following the CFG recommendations including that meeting the recommendations would require substantive changes to their current dietary patterns, time constraints, and limited knowledge regarding how to select and prepare plantbased proteins.

Most parents in this study reported being aware of the 2019 CFG. This is similar to previous survey research which found that awareness of the 2019 CFG was high among Canadian adults (Charlebois et al. 2021). Awareness of the 2007 CFG has also been shown to be high, with over $80 \%$ of Canadian adults stating they have heard of the 2007 Food Guide (Slater and Mudryj 2018). While awareness of the CFG is high, this awareness does not appear to translate into Canadians meeting the dietary recommendations promoted in the CFG (Mathe et al. 2015; Slater and Mudryj 2018; Vanderlee et al. 2015). The current findings regarding parents' perceptions of CFG and challenges in meeting the CFG may help explain this gap. For example, parents identified that many of the foods available in their food environment and the social norms regarding children's eating did not align with the 2019 CFG recommendations. Previous Canadian research has shown that many of the places where children and families spend their time, including schools (APCCDP 2020) and recreation centres (Olstad et al. 2020), offer a high number of highly processed foods, which are high in fat, sugar and salt and therefore would not fit with CFG recommendations. Social norms within these environments may also promote eating habits (Orava et al. 2017) 
that do not fit the recommendations. The majority of foods that are marketed and promoted to families also do not fit the 2019 CFG recommendations (Potvin Kent et al. 2019) Policy approaches to create food environments that reinforce healthy eating habits by limiting the availability and marketing of highly processed foods that are high in fat, salt and sugar and promoting the availability of foods, such as fruits and vegetables, are needed to support families in their efforts to meet the 2019 CFG recommendations.

As reported in numerous studies with parents of young children (Lindsay et al. 2018), time constraints were reported as a significant barrier in meeting the 2019 CFG recommendations, in particular to the recommendations of "limit highly processed foods" and "cook more often". In a study of over 1100 Ontario parents, Jarvis et al. (2017) found that lack of time was the most frequently cited barrier to support children's healthy eating. Workplace policies that aim to support parents' work-life balance or programmatic strategies (Bauer et al. 2012) to facilitate meal preparation for families may have positive implications on family eating patterns. Example of strategies may be food literacy programs aimed at engaging all family members in meal preparation (Lavelle et al. 2019).

Participants, particularly those who were not born in Canada, discussed how their traditional foods were not represented within the 2019 CFG, making it challenging to follow the recommendations. Similar findings were found among Spanish-speaking Latin American and Tamil-speaking Sri Lankan mothers of young children (Anderson et al. 2015) who identified that the foods depicted in the 2007 CFG did not reflect their traditional foods. The lack of representation of traditional foods on the CFG can lead to incorrect assumptions that traditional foods are not healthy or recommended (Anderson et al. 2015). While the 2019 CFG has been translated to over 30 languages, adaptations of the CFG to include traditional foods for various cultural groups in Canada could support adherence to the recommendations among these communities. Clinicians can also help translate how traditional foods and dietary patterns can fit within the 2019 CFG recommendations for various cultural groups.

Regarding the CFG recommendation to "Choose protein foods that come from plants more often", parents expressed challenges in identifying protein foods that come from plants as well as challenges in knowing how to prepare those foods. A lack of clarity in the definition of plant-based proteins and their food sources has been previously noted (Stok et al. 2017). The present results suggest that plant-based proteins need to be clearly defined for users. In addition, tools to support procurement and preparation of plant-based proteins would likely increase adherence to this guideline. While Health Canada has created and promoted numerous recipes that fit with the 2019 CFG guidelines, including a number that focuses on plant-based proteins, which are available on the Food Guide website, none of the parents in our study discussed accessing or using these recipes. Data collection for this study was from October 2019-January 2020; it is possible that the use of these recipes has increased among parents with longer exposure to these resources. However, the results of the current study suggest that additional support as well as increased promotion of the existing resources, i.e., recipes, to support families to be able to identify, procure, and prepare plant-based protein foods allowing for more families to meet these guidelines.

Some parents in our study also expressed concern about certain plant-based food sources being classified as processed foods. However, terms referring to the degree of food processing can be more misleading than explanatory (Knorr and Watzke 2019). It has been argued that foods classified based on the degree of food processing overlook the nutrients provided in these foods. A strict interpretation of their classification scheme suggests that the human body reacts to processing and not to nutrients, including those that appear during processing (Knorr and Watzke
2019). For example, plant-based proteins, such as soy beverages or tofu, are processed, being that they undergo several processes in production, but also provide key nutrients, including protein.

These results also suggest that additional guidance and clarification that milk and lower fat dairy products, such as cheese and yogurt are healthy protein choices that are needed to help parents understand the 2019 CFG recommendations. As shown in previous qualitative research with Canadian parents (Laila et al. 2021), some parents believed that dairy products were omitted from the 2019 CFG suggesting that dairy products were no longer considered healthy for them or their children. Milk and dairy products are key sources of proteins, vitamin D and calcium, which have been identified as key nutrients of concern among children in Canada (Leme et al. 2020, 2021).

While an analysis that compared the methodological quality of the 2007 and 2019 CFGs using criteria created by the World Health Organization found that the 2019 guidelines were more evidence-based than the 2007 recommendations (Dai et al. 2020) some parents in the present study expressed concern about whether the 2019 CFG was sufficiently evidence-based. Parents discussed how it seemed like findings from nutrition research and nutrition messaging were changing frequently, which made it difficult to trust or judge whether the CFG recommendations were correct. As reported by Miller et al. (2006) effectively communicating evidence-based nutrition information can be difficult in our current media environment, which is flooded with nutrition misinformation. While Health Canada has created documents that outline the evidence behind the 2019 CFG recommendations, additional promotion and plain-language explanations of how evidence informed these recommendations (Garza et al. 2019) may help to increase the public's trust in the science behind the CFG recommendations.

The following limitations to the present research should be noted: (1) the lack of sample diversity, with a high percentage of parents who self-identified as white; (2) contextual characteristics such as the focus on a single geographic region; and (3) the study design (qualitative nature) all of which limit the generalizability of our findings. However, the objective of this study was to develop a rich understanding of parents' perceptions of the 2019 CFG, which is currently absent in the literature.

These findings have implications for further development of the CFG, public health policies, and programmatic strategies to support families with preschool and school-age children. Specifically, these findings suggest that additional information regarding what counts as a protein food, including defining proteins from plant foods, how traditional foods from various cultures can fit within the 2019 CFG recommendations, and the process involved in developing the CFG may increase parents' trust related to CFG recommendations as well as increase their knowledge and understanding of the CFG recommendations. These findings also suggest that programmatic strategies to help families develop skills to select and prepare foods that fit within CFG recommendations as well as policies to create food environments that reinforce healthy eating habits are needed to support families in their efforts to meet the 2019 CFG recommendations.

\section{Conclusion}

The results suggest that most parents were aware of the 2019 CFG and many identified that the guide was visually appealing and less biased from the food industry as compared with previous guides. Parents also reported that the focus on eating behaviours could support healthy eating among their families. Parents expressed concerns about the CFG 2019 providing insufficient information about plant-based proteins, its "exclusion" of dairy products, and the lack of cultural representation in the guide. These perceptions as well as parents' perceived challenges in following these guidelines suggest that recommendations and 
messages may need to be revised and/or clarified and that policy and intervention approaches are needed to ensure that parents have adequate support to implement the guidelines within their families.

\section{Conflict of interest statement}

The authors declare there are no competing interests.

\section{Data availability statement}

No new data were created or analyzed in this study. Data sharing is not applicable to this article.

\section{Acknowledgements}

This research was supported by the São Paulo Research Foundation (FAPESP) (process no. 15/20852-7, the International Society for Behavioral Nutrition and Physical Activity Pioneers Program (2020), and the Helderleigh Foundation. Author contributions: A.C.B.L., J.H., and R.M.F. designed the research; A.C.B.L., A.L., and S.H. conducted the research, coded the focus group interview transcripts, and analyzed and interpreted the data. J.H. provided mediation for interpretation of the results; A.C.B.L. wrote the first draft; A.L., D.W.L.M., J.H., M.F., R.M.F., and S.H. reviewed, commented, and provided edits to the final version. J.H., D.W.L.M., R.M.F., and M.F. provided funding to support this work. All authors have read and approved the final manuscript.

\section{References}

Anderson, L.C., Mah, C.L., and Sellen, D.W. 2015. Eating well with Canada's food guide? Authoritative knowledge about food and health among newcomer mothers. Appetite, 91: 357-365. doi:10.1016/j.appet.2015.04.063. PMID:25936339.

APCCDP. 2020. Alberta's 2020 nutrition report card on food environments for children and youth. Alberta Policy Coalition for Chronic Disease Prevention (APCCDP), Edmonton, Alta.

Bauer, K.W., Hearst, M.O., Escoto, K., Berge, J.M., and Neumark-Sztainer, D. 2012. Parental employment and work-family stress: associations with family food environments. Soc. Sci. Med. 75(3): 496-504. doi:10.1016/j.socscimed.2012. 03.026. PMID:22591825

Braun, V., and Clarke, V. 2006. Using thematic analysis in psychology. Qual. Res. Psychol. 3(2): 77-101. doi:10.1191/1478088706qp063oa.

Buus, N., and Perron, A. 2020. The quality of quality criteria: replicating the development of the Consolidated Criteria for Reporting Qualitative Research (COREQ). Int. J. Nurs. Stud. 102: 103452. doi:10.1016/j.ijnurstu.2019.103452. PMID:31726311.

Charlebois, S., Wambui, B., Racey, M., Fiander, D., Music, J., and Somogyi, S. 2021. Canada's Food Guide: awareness, understanding, affordability, and barriers to adoption (preliminary results). Dalhousie University, Halifax, NS.

Dai, Z., Kroeger, C.M., Lawrence, M., Scrinis, G., and Bero, L. 2020. Comparison of methodological quality between the 2007 and 2019 Canadian dietary guidelines. Public Health Nutr. 23(16): 2879-2885. doi:10.1017/S1368980020000956. PMID:32552917.

Fabbri, A., Holland, T.J., and Bero, L.A. 2018. Food industry sponsorship of academic research: investigating commercial bias in the research agenda. Public Health Nutr. 21(18): 3422-3430. doi:10.1017/S1368980018002100. PMID: 30157979.

Faulkner, S.L., and Trotter, S.P. 2017. Data saturation. In The International Encyclopedia of Communication Research Methods. pp. 1-2. doi:10.1002/ 9781118901731.iecrm0060.

Garza, C., Stover, P.J., Ohlhorst, S.D., Field, M.S., Steinbrook, R., Rowe, S., et al. 2019 Best practices in nutrition science to earn and keep the public's trust. Am. J. Clin. Nutr. 109(1): 225-243. doi:10.1093/ajcn/nqy337. PMID:30657846.

Health Canada. 2019. Canada's dietary guidelines for health professionals and policy makers. Health Canada, Ottawa, Ont.

Health Canada. 2021. Revision process for Canada's Food Guide. Government of Canada, Ottawa, Ont. Available from https://www.canada.ca/en/ health-canada/services/canada-food-guides/revision-process.html\#a4.

Hui, A. 2017. A taste of what's to come: inside the big revamp of Canada's Food Guide. The Globe and Mail 18 July, 2017. Available from https://www. theglobeandmail.com/news/national/a-taste-of-whats-to-come-inside-the-bigrevamp-of-canadas-food-guide/article35728046/.

Jarvis, J.W., Harrington, D.W., and Manson, H. 2017. Exploring parent-reported barriers to supporting their child's health behaviors: a cross-sectional study. Int. J. Behav. Nutr. Phys. Act. 14(1): 77. doi:10.1186/s12966-017-0508-9. PMID: 28587672.

Kitzinger, J. 1995. Qualitative research: introducing focus groups. BMJ, 311(7000): 299-302. doi:10.1136/bmj.311.7000.299. PMID:7633241.
Knorr, D., and Watzke, H. 2019. Food processing at a crossroad. Front. Nutr. 6: 85 . doi:10.3389/fnut.2019.00085. PMID:31294027.

Krueger, R. and Casey, M.A. 2015. Focus group: a practical guide for applied research. 5th ed. Sage Publishing, Thousand Oaks, Calif.

Laila, A., Topakas, N., Farr, E., Haines, J., Ma, D.W., Newton, G., and Buchholz, A.C. 2021. Barriers and facilitators of household provision of dairy and plantbased dairy alternatives in families with preschool-age children. Public Health Nutr. 1-13. [Online ahead of print.] doi:10.1017/S136898002100080X. PMID:33602360.

Lavelle, F., Benson, T., Hollywood, L., Surgenor, D., McCloat, A., Mooney, E., et al. 2019. Modern transference of domestic cooking skills. Nutrients, 11(4): 870. doi:10.3390/nu11040870. PMID:31003423.

Leme, A.C., Baranowski, T., Thompson, D., Philippi, S., O’Neil, C.E., Fulgoni, V.L., and Nicklas, T.A. 2020. Food sources of shortfall nutrients among US adolescents: National Health and Nutrition Examination Survey (NHANES) 2011-2014. Fam. Community Health, 43(1): 59-73. doi:10.1097/FCH.0000000000000243. PMID:31764307.

Leme, A.C.B., Fisberg, R.M., Mello, A.V., Sales, C.H., Ferrari, G., Haines, J., et al. 2021. Food sources of shortfall nutrients among Latin Americans: results from the Latin American Study of Health and Nutrition (ELANS). Int. J. Environ. Res. Public. Health, 18: 4967. doi:10.3390/ijerph18094967. PMID:34067018.

Lindsay, A.C., Wallington, S.F., Lees, F.D., and Greaney, M.L. 2018. Exploring how the home environment influences eating and physical activity habits of low-income, Latino children of predominantly immigrant families: a qualitative study. Int. J. Environ. Res. Public Health, 15(5): 978. doi:10. 3390/ijerph15050978. PMID:29757941.

Mathe, N., Van der Meer, L., Agborsangaya, C.B., Murray, T., Storey, K., Johnson, J.A., et al. 2015. Prompted awareness and use of eating well with Canada's Food Guide: a population-based study. J. Hum. Nutr. Diet. 28(1): 64-71. doi:10.1111/jhn. 12222. PMID:24580728.

Miller, G.D., Cohen, N.L., Fulgoni, V.L., Heymsfield, S.B., and Wellman, N.S. 2006. From nutrition scientist to nutrition communicator: why you should take the leap. Am. J. Clin. Nutr. 83(6): 1272-1275. doi:10.1093/ajcn/83.6.1272. PMID:16762936.

Morgan, D. 1993. Successful focus groups: advancing the state of the art. SAGE, Thousand Oaks, Calif. doi:10.4135/9781483349008.

O.Nyumba, T., Wilson, K., Derrick, C.J., and Mukherjee, N. 2018. The use of focus group discussion methodology: insights from two decades of application in conservation. Methods Ecol. Evol. 9(1): 20-32. doi:10.1111/2041-210X.12860.

Olstad, D.L., Prowse, R.J.L., Raine, K.D., Tomlin, D., Kirk, S.F., McIsaac, J.-L.D., et al. 2020. Baseline results from the Eat, Play, Live trial: a randomized controlled trial within a natural experiment examining the role of nutrition policy and capacity building in improving food environments in recreation and sport facilities. Food Pol. 92: 101870. doi:10.1016/j.foodpol.2020.101870.

Ontai, L.L., Sutter, C., Sitnick, S., Shilts, M.K., and Townsend, M.S. 2020. Parent food-related behaviors and family-based dietary and activity environments: associations with BMI z-scores in low-income preschoolers. Child Obes. 16(S1): S55-S63. doi:10.1089/chi.2019.0105. PMID:31682151.

Orava, T., Manske, S., and Hanning, R. 2017. Support for healthy eating at schools according to the comprehensive school health framework: evaluation during the early years of the Ontario School Food and Beverage Policy implementation. Health Promot. Chronic Dis. Prev. Can. 37(9): 303-312. doi:10. 24095/hpcdp.37.9.05. PMID:28902479.

Paquette, M.C. 2005. Perceptions of healthy eating: state of knowledge and research gaps. Can. J. Public Health, 96(Suppl. 3): S15-S19, S16-S21. doi:10.1007| BF03405196. PMID:16042159.

Patel, P., and Mannion, C. 2019. Maternal impressions of the new 2019 Canadian Food Guide. CASCH Special Issue, 2(3): 5. doi:10.29173/aar86.

Potvin Kent, M., Velazquez, C.E., Pauzé, E., Cheng-Boivin, O., and Berfeld, N. 2019. Food and beverage marketing in primary and secondary schools in Canada. BMC Public Health, 19(1): 114-114. doi:10.1186/s12889-019-6441-x. PMID:30691422.

Seed, B., and Rocha, C. 2018. Can we eat our way to a healthy and ecologically sustainable food system? Can. Food Studies, 5(3): 182-207. doi:10.15353/ cfs-rcea.v5i3.258.

Slater, J.J., and Mudryj, A.N. 2018. Are we really "eating well with Canada's food guide”? BMC Public Health, 18(1): 652. doi:10.1186/s12889-018-5540-4. PMID:29788941

Stok, F.M., Hoffmann, S., Volkert, D., Boeing, H., Ensenauer, R., StelmachMardas, M., et al. 2017. The DONE framework: creation, evaluation, and updating of an interdisciplinary, dynamic framework 2.0 of determinants of nutrition and eating. PLoS One, 12(2): e0171077. doi:10.1371/journal.pone. 0171077. PMID:28152005.

Vanderlee, L., McCrory, C., and Hammond, D. 2015. Awareness and knowledge of recommendations from Canada's Food Guide. Can. J. Diet. Pract. Res. 76(3): 146-149. doi:10.3148/cjdpr-2015-014. PMID:26280795.

Wijayaratne, S., Westberg, K., Reid, M., and Worsley, A. 2021. A qualitative study exploring the dietary gatekeeper's food literacy and barriers to healthy eating in the home environment. Health Promot. J. Austr. 23(Suppl. 2): 292300 doi:10.1002/hpja.398.10.1002/hpja.398. PMID:32761932.

Zarychta, K., Banik, A., Kulis, E., Boberska, M., Radtke, T., Chan, C.K.Y., et al. 2020. Do parent-child dyads with excessive body mass differ from dyads with normal body mass in perceptions of obesogenic environment? Nutrients, 12(7): 2149. doi:10.3390/nu12072149. PMID:32707698. 